\title{
Retention of Bioactive Compounds During Domestic Processing of Croatian Domestic Garlic (Allium sativum L.)
}

\author{
Sandra Pedisić ${ }^{1}$, Zoran \\ Zorić ${ }^{*}$, Anđela Miljanović \\ Danijela Šimić ${ }^{2}$ Maja \\ Repajić ${ }^{2}$ and \\ Verica Dragović-Uzelac ${ }^{2}$
}

'Faculty of Food Technology and Biotechnology, University of Zagreb, Petra Kasandrića 3, HR-23000 Zadar, Croatia

${ }^{2}$ Faculty of Food Technology and Biotechnology, University of Zagreb, Pierottijeva 6, HR-10000 Zagreb, Croatia

Received: 6 February 2018 Accepted: 4 October 2018

\footnotetext{
*Corresponding author:

Phone: +38523331077 ;

Fax: +38523331089;

E-mail:zzoric@pbf.hr
}

ORCID IDs: 0000-0002-5491-0128 (Pedisić), 0000-0002-9386-374X (Zorić), 0000-0002-7359-1943 (Miljanović), 0000-0002-6901-4537 (Šimić), 0000-0001-8413-5575 (Repajíć), 0000-0002-4179-3727 (Dragović-Uzelac)

\section{SUMMARY}

The content of bioactive compounds and antioxidant activity were determined in Croatian domestic garlic after domestic processing (crushing, water blanching and frying) through different thermal treatments. The predominant phenolics in fresh garlic expressed per fresh mass were $p$-coumaric $(10.79 \mathrm{mg} / 100 \mathrm{~g})$ and caffeic $(9.50 \mathrm{mg} / 100$ g) acids, while the most abundant organosulfur compounds were methylsulfinylsulfanylmethane $(9881.84 \mathrm{mg} / 100 \mathrm{~g}), 3$-methylsulfinylsulfanylprop-1-ene and 3-methylsulfanylsulfinylprop-1-ene $(257.59 \mathrm{mg} / 100 \mathrm{~g})$ and allicin $(185.62 \mathrm{mg} / 100 \mathrm{~g})$. The highest total phenolic content and antioxidant activity were determined in fresh garlic followed by crushed, blanched and fried garlic, while organosulfur content increased after shorter thermal treatment. As time of treatment increased, frying showed the most pronounced losses of garlic total phenolic acids (in the range from 19.47 to $37.93 \%$ ) and blanching of organosulfur content (about $25 \%$ ). The blanching and frying significantly reduced allicin content, while S-methyl methanesulfinothioate was more stable.

Key words: Croatian domestic garlic, thermal treatment, domestic processing, bioactive compounds, antioxidant activity

\section{INTRODUCTION}

Garlic (Allium sativum L.) is one of the most important vegetable crops that have been used for centuries as a food and spice. It contains numerous bioactive molecules such as polyphenols and organosulfur compounds (OSC) responsible for organoleptic properties and for potential pharmacological properties, such as antioxidant, anticancer, anti-atherosclerotic, antibacterial, antiviral, and anti-inflammatory effects (1). Many studies have reported that phenols and particular OSC present in higher concentrations are responsible for high antioxidant potential of garlic (2). The main groups of polyphenols present in considerable amounts in garlic are hydroxycinnamic acids ( $p$-coumaric, ferulic, sinapic and caffeic acids) and flavonols (myricetin, quercetin, apigenin and kaempferol) (3). The OSC present in intact garlic cloves are $\gamma$-glutamyl cysteine and cysteine sufoxydes including alliin. After processing (cutting, peeling, crushing, shredding, blanching, boiling, frying, etc.), increased exposure to oxygen causes the formation of many sulfur compounds with important biological activities. Release of the vacuolar enzymes such as allinase catalyses the formation of sulfenic acids from alliin, which spontaneously reacts and forms unstable thiosulfinates, mostly allicin, responsible for typical pungent smell. Unstable allicin breaks down in a variety of forms of fat-soluble sulfur-containing compounds such as diallyl sulfide (DAS), diallyl disulfide (DADS), or diallyl trisulfide (DATS). The $\gamma$-glutamyl cysteine convertes to water-soluble compounds such as S-allyl cysteine (SAC), which contributes to the health benefits of some garlic preparations (4). At the same time, these processes degrade phenolics and change their effectiveness, structure and content $(3,5)$. Some literature data have shown significant decrease of garlic phenolic and organosulfur content and antioxidant activity after boiling and frying (6), while in other studies phenolic content and antioxidant activity of garlic was not significantly affected $(3,7)$. These differences in stability of garlic bioactive compounds were determined particularly after 
prolonged exposure to higher temperatures during thermal treatments (8). For example, in blanched garlic the thiosulfinate content and antioxidant activity significantly decreased as the processing time and temperature increased (9). Crushing of garlic cloves (especially before cooking) is the most preferable cooking treatment because of the formation of OSC and alleviated reduction of the thiosulfinate content (10). Garlic has various culinary uses worldwide, but only a limited number of reports evaluate the retention of garlic bioactive compounds and antioxidant activity before and after domestic processing $(3,8,10,11)$.

Therefore, the aim of this study is to evaluate the retention of polyphenols, OSC and antioxidant activity of Croatian domestic garlic cultivar during generally applied domestic processing (crushing, water blanching at $100^{\circ} \mathrm{C}$ and frying at $\left.120^{\circ} \mathrm{C}\right)$ at four different treatment times $(2,5,8$ and $10 \mathrm{~min})$.

\section{MATERIALS AND METHODS}

\section{Sample preparation and processing}

Ecologically cultivated Croatian domestic garlic white cul-

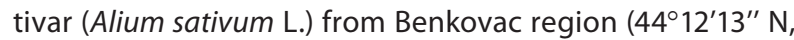
$15^{\circ} 58^{\prime} 16^{\prime \prime}$ E) was used for research. After harvesting, garlic was cured at $25^{\circ} \mathrm{C}$ for 15 days before analysis. Fresh cloves of garlic serving as control sample were cleaned, peeled, chopped into small pieces with a knife and crushed with a mixer (AR100; Moulinex, Écully, France) for approx. $0.5 \mathrm{~min}$, immediately weighed and subjected to extraction of phenolic and organosulfur compounds (OSC). Crushed fresh garlic sample was left standing in air for 2, 5, 8 and $10 \mathrm{~min}$ at room temperature and subjected to extraction.

Water blanching and frying effects were tested with uncrushed garlic. Blanching was done in water bath (MPC 215/B; Huber, Berching, Germany) operating at $100{ }^{\circ} \mathrm{C}$ and frying was carried out without fat in a cover double fry pan (RI-1201; Royalty Line, Zürich, Switzerland) at $120^{\circ} \mathrm{C}$. All garlic samples were also subjected to the above-mentioned treatments for 2, 5, 8 and $10 \mathrm{~min}$, cooled at room temperature and mixed into a fine paste, weighed and rapidly subjected to extraction for the determination of phenolic content and OSC. All treatments were done in two replicates, using $100 \mathrm{~g}$ of garlic for each individual run.

\section{Reagents}

All solvents and reagents were of HPLC and analytical grade and purchased from Merck (Darmstadt, Germany) and Sigma-Aldrich (St. Louis, MO, USA). Phenolic standards (gallic acid (GA), caffeic acid (CA), ferulic acid (FA) and $p$-coumaric acid ( $p$-CA), quercetin-3-glucoside (Q-3-G) and kaempferol-3-rutinoside (K-3-R) were purchased from Sigma-Aldrich Chemie $\mathrm{GmbH}$ (Steinheim, Germany). Diallyl thiosulfinate (allicin) was purchased from ChromaDex, Irvine, CA, USA.

\section{Extraction of polyphenolic compounds}

The polyphenolic compounds were extracted according to previously described procedure with minor modifications (12). Polyphenols were extracted from garlic samples $(2.000 \pm 0.001)$ $\mathrm{g}$ with $10 \mathrm{~mL}$ of $100 \%$ methanol solvent, homogenised with a magnetic stirrer (VELP Scientifica Srl, Usmate, Italy) for 30 min and transferred in ultrasound bath (Elmasonic S $40 \mathrm{H}$; Elma Schmidbauer $\mathrm{GmbH}$, Singen, Germany) at $50^{\circ} \mathrm{C}$ for $30 \mathrm{~min}$. The contents were filtered into a $25-\mathrm{mL}$ flask and extraction was repeated. Afterwards, extracts were combined in $25-\mathrm{mL}$ volumetric flasks, and made up to volume with extraction solvent. Each sample was treated in two replicates, and each replicate was extracted twice $(N=4)$. Extracts were stored at $-60^{\circ} \mathrm{C}$ in an inert nitrogen gas atmosphere before analysis. These extracts were also used for the spectrophotometric and HPLC determination of phenolic compound content and antioxidant activity (AOA). Before injection in HPLC column, garlic extracts were filtered through a $0.45-\mathrm{mm}$ pore size membrane filter (Macherey-Nagel GmbH \& Co. KG, Düren, Germany).

\section{Extraction of organosulfur compounds}

The extraction of organosulfur compounds (OSC) was performed according to previously described procedure (13) with some modifications. OSC were extracted from garlic samples $(5.000 \pm 0.001) \mathrm{g}$ with $20 \mathrm{~mL}$ distilled water, homogenised in a vortex mixer (ZX3; VELP Scientifica Srl) for $1 \mathrm{~min}$ and centrifuged at 2800×g for 5 min (Z 206 A; Hermle Labortechnik GmbH, Wehingen, Germany). The supernatants $(1 \mathrm{~mL}$ ) were transferred in 2.5-mL Eppendorf tubes (Sarstedt AG \& Co. KG, Nümbrecht, Germany) and $1 \mathrm{~mL}$ acetonitrile was added, homogenised in a vortex (ZX3; VELP Scientifica Srl) for $1 \mathrm{~min}$ and centrifuged at $112 . \mathrm{g}$ for $5 \mathrm{~min}$. Afterwards, supernatants were filtered through $0.25-\mu \mathrm{M}$ nylon syringe filters (VWR-International, Darmstadt, Germany) and placed directly into HPLC vials and injected on HPLC column.

\section{Analysis of total phenolic content}

The total phenolic content (TPC) of garlic extracts was quantified spectrophotometrically using Folin-Ciocalteu reagent and gallic acid as standard (14). Mixtures were prepared by combining $100 \mu \mathrm{L}$ diluted garlic extract (garlic extract/distilled water 1:10) with $200 \mu \mathrm{L}$ Folin-Ciocalteu reagent and 2 $\mathrm{mL}$ sodium carbonate solution. After $120 \mathrm{~min}$ of incubation at room temperature, the absorbance was read at $735 \mathrm{~nm}$ (UNICAM HEXIOS $\beta$ UV-Vis spectrometer; Thermo Spectronic, Cambridge, UK). Results are expressed in milligrams of gallic acid equivalents per $100 \mathrm{~g}$ of fresh mass, as mean value \pm standard deviation ( $N=3$ replicates for each of the four extractions).

\section{Antioxidant activity}

The AOA was determined according to ferric reducing antioxidant power (FRAP) assay as previously reported (15). The assay was based on the reduction of the $\mathrm{Fe}^{3+}$ tripyridyltriazine 
(TPTZ) complex to a ferrous form $\left(\mathrm{Fe}^{2+}\right)$ at low $\mathrm{pH}$. FRAP values are expressed in mmol of Trolox equivalents per $100 \mathrm{~g} \mathrm{fm}$, as mean value \pm standard deviation ( $N=3$ replicates for each one of the four extractions).

\section{HPLC analysis of polyphenolic and organosulfur compounds}

The chromatographic separation was performed using Agilent Infinity 1260 system equipped with Agilent 1260 photodiode array detector (PDA; Agilent Technologies Inc., Santa Clara, CA, USA) with an automatic injector and Chemstation software v. C.01.03 (16).

The separation of polyphenols and OSC was performed using a Nucleosil 100-5C18 column (250 mm×4.6 mm, i.d. 5 $\mu \mathrm{m}$; Macherey-Nagel GmbH \& Co. KG). The solvent composition and used gradient conditions for phenolic and organosulfur determination were as described previously $(17,18)$. PDA detection was performed in range from 220 to $420 \mathrm{~nm}$. Compound identification was based on retention times of identified compounds and standards and comparison with characteristic spectra and literature data (phenolic acids were identified at $280 \mathrm{~nm}$, flavonol glycoside at $360 \mathrm{~nm}$ and allicin at $240 \mathrm{~nm})(17,19)$. Working phenolic acid standard solutions were prepared by diluting the stock solution to yield five concentrations in a range from 2.3 to $50 \mathrm{mg} / \mathrm{L}$. Quantitative determination of phenolic acids was carried out using the calibration curves of the standards ( $G A: y=17.213 x, R^{2}=0.997 ; C A$ : $y=21.149 x, R^{2}=0.988 ; F A: y=19.193 x, R^{2}=0.991 ; p-C A: y=10.691 x$; $R^{2}=0.989$ ). Flavonol glycoside standard solution was prepared by diluting the stock solution to yield five concentrations in range from 1.0 to $20 \mathrm{mg} / \mathrm{L}\left(\mathrm{Q}-3-\mathrm{R}\right.$ : $\mathrm{y}=10.214 \mathrm{x}, \mathrm{R}^{2}=0,989$; $\mathrm{K}-3-\mathrm{R}$ : $\left.\mathrm{y}=10.176 \mathrm{x}, \mathrm{R}^{2}=0.996\right)$. The protocatechuic and $p$-hydroxybenzoic acids were expressed as equivalents of gallic acid. Working allicin standard solutions were prepared by diluting the stock solution to yield five concentrations in a range from 8.33 to $100 \mathrm{mg} / \mathrm{L}$. The quantification of individual OSC was calculated on fresh mass basis as allicin equivalents $(\mathrm{mg} / 100 \mathrm{~g})$ using the equation based on the calibration curve $\left(y=36.415 x, R^{2}=0.994\right)$.

\section{Statistical analysis}

All measurements were performed in triplicate and the results are presented as mean \pm standard deviation (S.D.). Differences between mean values were compared by least significant difference (LSD) in a one-way analysis of variance (ANOVA) using the Statistica v. 10.0 (20). In order to explore the influence of treatment time and type of processes on phenolic and OSC content and AOA, ANOVA was performed and marginal mean values were compared with Tukey's honestly significant difference (HSD) test. Differences with $\mathrm{p} \leq 0.05$ were considered significant.

\section{RESULTS AND DISCUSSION}

Croatian domestic garlic cultivar was exposed to air after crushing and subjected to procedures of water blanching and frying over a period of 2, 4, 8 and $10 \mathrm{~min}$ in order to observe the effect of the type of treatment on the total phenolic content (TPC), polyphenolic compounds, organosulfur compounds (OSC) and antioxidant activity (AOA), respectively. The fresh crushed Croatian domestic garlic served as control sample for calculation of the retention of TPC, polyphenolic compounds, OSC and AOA during each applied processes (crushing, boiling and frying).

\section{Total phenolic content and antioxidant activity}

The effect of crushing, blanching and frying on TPC and AOA of Croatian domestic garlic cultivar determined spectrophotometrically is shown in Fig. 1. The initial TPC in fresh Croatian domestic garlic sample was $78.02 \mathrm{mg} / 100 \mathrm{~g}$, which was lower than previously reported results for different garlic cultivars grown in Spain (12). However, great variation in the TPC among the various cultivars depends on the genetics, cultivation practices and growing conditions (21).

In processed garlic samples, TPC on fresh mass basis ranged from 42.98 to $54.55 \mathrm{mg} / 100 \mathrm{~g} \mathrm{fm}$ and generally better retention of TPC was observed in crushed garlic than in fried and blanched ones. Compared to fresh garlic, in this study TPC loss was $31.8 \%$ in crushed, $38.5 \%$ in fried and $44.92 \%$ in blanched garlic after 10 min of treatment, which is in agreement with previous results where TPC was higher in raw garlic than in boiled (-38\%) and fried (-44\%) (5), and also in other boiled vegetables lower TPC has been reported (22). The TPC decrease in blanched Croatian domestic garlic can be attributed to the solubility of phenols and their diffusion into the boiling water (5). The highest TPC decrease in all treated garlic samples was after 2 min of treatment (about $30 \%$ ), but until the end of the treatments TPC changed significantly in blanched and fried samples. Applied processes probably formed different types of phenolic bonds and TPC decrease is most probably caused by breakdown of some heat-labile phenolic compounds, temperature-induced chemical oxidation and release of oxidative and hydrolytic enzymes that could destroy the antioxidant compounds in vegetables (23). Exposure to air also enhanced oxidation processes and enzyme activity. On the other hand, some authors observed that the garlic phenolic content increased after cooking (11), which is probably connected with applied processing conditions (temperature and time).

Similar to the phenolic content, the AOA, expressed as Trolox equivalents, of phenolic extracts obtained from crushed and fried garlic after 2 min of treatment decreased about 2.5-fold and in blanched garlic 4-fold, as compared to that of fresh garlic $(0.88 \mathrm{mmol} / 100 \mathrm{~g})$; however, AOA loss was not proportional to the time of treatment and to TPC. Frying was found to be less aggressive than blanching and generally crushed garlic exposed to air had higher AOA. The highest 


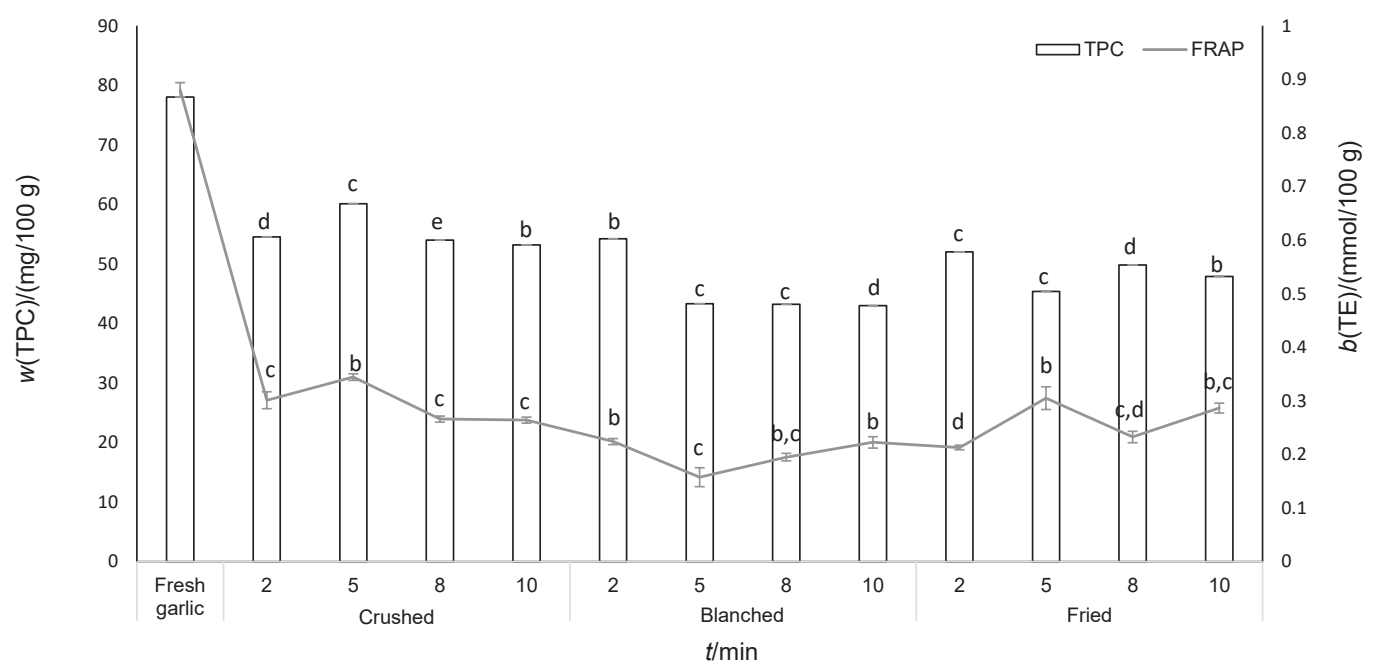

Fig. 1. Total phenolic content (TPC) and antioxidant activity (FRAP), expressed as Trolox equivalents (TE), on fresh mass basis, in fresh and processed (crushed, blanched or fried) Croatian domestic garlic after 2, 5, 8 and 10 min of treatment. The same letters on the line and on the bar indicate that the differences are not statistically significant at $\mathrm{p} \geq 0.05$

AOA, expressed as Trolox equivalents, of crushed and fried garlic was at $5 \mathrm{~min}(0.34$ and $0.31 \mathrm{mmol} / 100 \mathrm{~g})$ and of blanched garlic at 2 and $10 \mathrm{~min}$ of heating $(0.22 \mathrm{mmol} / 100 \mathrm{~g})$. The statistical analysis showed that type of treatment, particularly blanching, affected TPC and AOA of Croatian domestic garlic, while time of treatment had no significant effect. According to literature data, all types of processes reduced the AOA of garlic $(6,7)$. Blanching and frying of Polish garlic did not decrease significantly the level of AOA and the phenolic content (3). The cooking processes had both positive and negative impact on the phenolic concentration and AOA depending on the relative intensities of these processes and the nature of phenolic compounds present in different vegetables (24).

\section{HPLC analysis of phenolics in fresh and processed Croatian domestic garlic}

Using HPLC UV/Vis PDA in fresh and processed Croatian domestic garlic, six phenolic acids were determined: gallic $(\mathrm{GA})$, protocatechuic (proC), $p$-hydroxybenzoic ( $p$-HBA), caffeic (CA), $p$-coumaric ( $p$-CA) and ferulic (FA) (Table 1). Their content, on fresh mass basis, in fresh garlic was in range from 0.13 to $10.79 \mathrm{mg} / 100 \mathrm{~g}$, which was higher than in reported Polish garlic cultivar (25). The predominant phenolic acids were $p$-CA (10.79 mg/100 g), CA $(9.50 \mathrm{mg} / 100 \mathrm{~g})$ and proC $(5.30 \mathrm{mg} / 100 \mathrm{~g})$, which comprised more than $85 \%$ of total phenolic acid content (sum of individual phenolic acids). The $p$-HBA and ferulic acid (2.15 and $2.06 \mathrm{mg} / 100 \mathrm{~g}$ respectively)

Table 1. Phenolic compounds determined on fresh mass basis by HPLC UV/Vis PDA in fresh and processed (crushed, blanched or fried) Croatian domestic garlic after 2, 5, 8 and 10 min of treatment

\begin{tabular}{|c|c|c|c|c|c|c|c|c|}
\hline \multirow{2}{*}{$\begin{array}{l}\text { Croatian } \\
\text { domestic garlic }\end{array}$} & \multirow{2}{*}{$t / \mathrm{min}$} & GA & proC & $p$-HBA & CA & $p$-CA & FA & TP \\
\hline & & \multicolumn{6}{|c|}{$w /(\mathrm{mg} / 100 \mathrm{~g})$} & \\
\hline \multirow[t]{2}{*}{ Fresh } & 0 & $0.13 \pm 0.01$ & $5.30 \pm 0.02$ & $2.15 \pm 0.03$ & $9.50 \pm 0.04$ & $10.79 \pm 0.03$ & $2.06 \pm 0.09$ & $29.93 \pm 0.11$ \\
\hline & 2 & $(0.11 \pm 0.01)^{\mathrm{a}}$ & $(3.83 \pm 0.05)^{b}$ & $(0.40 \pm 0.02)^{\mathrm{b}}$ & $(8.60 \pm 0.03)^{b}$ & $(9.73 \pm 0.03)^{b}$ & $(1.55 \pm 0.04)^{b}$ & $(24.22 \pm 0.02)^{\mathrm{b}}$ \\
\hline \multirow[t]{4}{*}{ Crushed } & 5 & $(0.10 \pm 0.01)^{\mathrm{a}}$ & $(2.15 \pm 0.02)^{c}$ & $(0.39 \pm 0.03)^{b}$ & $(7.01 \pm 0.16)^{c}$ & $(7.81 \pm 0.04)^{c}$ & $(1.52 \pm 0.02)^{b}$ & $(18.98 \pm 0.09)^{c}$ \\
\hline & 8 & $(0.09 \pm 0.01)^{\mathrm{a}}$ & $(2.10 \pm 0.03)^{c}$ & $(0.46 \pm 0.02)^{\mathrm{b}}$ & $(5.43 \pm 0.02)^{d}$ & $(6.22 \pm 0.03)^{d}$ & $(1.19 \pm 0.04)^{c}$ & $(15.49 \pm 0.02)^{d}$ \\
\hline & 10 & $(0.08 \pm 0.01)^{\mathrm{a}}$ & $(2.14 \pm 0.03)^{c}$ & $(0.42 \pm 0.03)^{\mathrm{a}}$ & $(5.44 \pm 0.01)^{d}$ & $(6.21 \pm 0.03)^{d}$ & $(1.20 \pm 0.02)^{c}$ & $(15.49 \pm 0.02)^{d}$ \\
\hline & 2 & $(0.09 \pm 0.02)^{\mathrm{a}}$ & $(4.03 \pm 0.04)^{b}$ & $(2.02 \pm 0.02)^{\mathrm{a}}$ & $(6.72 \pm 0.04)^{b}$ & $(7.70 \pm 0.04)^{b}$ & $(1.53 \pm 0.01)^{\mathrm{b}}$ & $(22.09 \pm 0.02)^{b}$ \\
\hline \multirow[t]{4}{*}{ Blanched } & 5 & $(0.09 \pm 0.01)^{\mathrm{a}}$ & $(3.68 \pm 0.01)^{c}$ & $(1.64 \pm 0.02)^{\mathrm{b}}$ & $(6.36 \pm 0.02)^{c}$ & $(7.23 \pm 0.03)^{c}$ & $(1.60 \pm 0.03)^{b}$ & $(20.60 \pm 0.08)^{c}$ \\
\hline & 8 & $(0.09 \pm 0.01)^{\mathrm{a}}$ & $(3.41 \pm 0.01)^{d}$ & $(1.51 \pm 0.03)^{c}$ & $(5.93 \pm 0.04)^{d}$ & $(6.87 \pm 0.01)^{d}$ & $(1.59 \pm 0.02)^{\mathrm{b}}$ & $(19.40 \pm 0.04)^{d}$ \\
\hline & 10 & $(0.08 \pm 0.02)^{\mathrm{a}}$ & $(3.39 \pm 0.03)^{d}$ & $(1.23 \pm 0.02)^{d}$ & $(5.50 \pm 0.03)^{\mathrm{e}}$ & $(6.27 \pm 0.02)^{\mathrm{e}}$ & $(1.55 \pm 0.04)^{b}$ & $(18.02 \pm 0.01)^{\mathrm{e}}$ \\
\hline & 2 & $(0.06 \pm 0.01)^{b}$ & $(3.10 \pm 0.03)^{b}$ & $(0.79 \pm 0.03)^{\mathrm{b}}$ & $(6.18 \pm 0.03)^{b}$ & $(7.03 \pm 0.02)^{\mathrm{b}}$ & $(1.70 \pm 0.02)^{b}$ & $(18.86 \pm 0.00)^{b}$ \\
\hline \multirow[t]{3}{*}{ Fried } & 5 & $(0.05 \pm 0.01)^{\mathrm{b}}$ & $(2.61 \pm 0.01)^{c}$ & $(0.72 \pm 0.02)^{\mathrm{b}}$ & $(4.73 \pm 0.02)^{c}$ & $(5.40 \pm 0.03)^{c}$ & $(1.67 \pm 0.01)^{b}$ & $(15.18 \pm 0.06)^{c}$ \\
\hline & 8 & $(0.04 \pm 0.00)^{b}$ & $(2.09 \pm 0.02)^{d}$ & $(0.75 \pm 0.01)^{b}$ & $(4.30 \pm 0.01)^{d}$ & $(4.91 \pm 0.02)^{d}$ & $(1.67 \pm 0.01)^{b}$ & $(13.76 \pm 0.04)^{d}$ \\
\hline & 10 & $(0.03 \pm 0.01)^{\mathrm{b}}$ & $(1.20 \pm 0.01)^{\mathrm{e}}$ & $(0.52 \pm 0.01)^{c}$ & $(4.08 \pm 0.03)^{\mathrm{e}}$ & $(4.65 \pm 0.02)^{\mathrm{e}}$ & $(1.22 \pm 0.00)^{c}$ & $(11.70 \pm 0.03)^{\mathrm{e}}$ \\
\hline
\end{tabular}

Values in the same row with the same letter in superscript do not differ statistically at $p \leq 0.05$.

$\mathrm{GA}=$ gallic acid, proC=protocatechuic acid, $\mathrm{p}-\mathrm{HBA}=\mathrm{p}$-hydroxybenzoic acid, $\mathrm{CA}=$ caffeic acid, $p$-CA=p-coumaric acid, $\mathrm{FA}=\mathrm{erulic}$ acid, $\mathrm{TP}=$ total phenolics 
were determined at similar concentrations in fresh crushed Croatian domestic garlic but 5 -fold lower than those of $p$-CA. Literature data define the highest concentrations of CA and FA in garlic $(3,12)$ although phenolic acid content is variable depending on the cultivar, agronomic practice or environmental differences (14). For instance, significant differences were observed between Spanish and Polish cultivars, where proC content, measured on dry mass basis, was not detected in Spanish cultivars, while in Polish cultivars it was relatively high $(0.36 \mathrm{mg} / 100 \mathrm{~g})(3,12)$. In our study, proC and $p$-HBA contents were higher than those determined in Polish cultivars.

Regarding the flavonol content, only quercetin was detected in trace amounts $(<0.1 \mathrm{mg} / 100 \mathrm{~g})$ in Croatian domestic garlic (not shown in Table 1), which was in agreement with previous studies (26)

The results of the present study indicated that type of treatment and time of treatment affect the degradation of phenolic compounds in Croatian domestic garlic. The less negative effects on phenolic acids were observed in blanched garlic as treatment time increased. Frying caused more pronounced losses of garlic total phenolic acid content (-60.89 $\%)$ than crushing (-48.22\%) and blanching (-39.78\%) after 10 min of treatment. Comparing the content of individual phenolic acids during blanching and frying, decrease of all phenolic acids was noticed as treatment time increased, which is in accordance with reported data (22).

After 10 min of treatment, results indicated that the lowest losses were of FA, particularly in the blanched garlic (-24.76 $\%)$, while the highest losses were of $p$-HBA in crushed garlic $(-80.47 \%)$ and of proC and GA acids in fried garlic (-77.36 and $-76.92 \%$ respectively). The statistical analysis (ANOVA) confirmed that frying decreased the contents of these compounds significantly more than crushing of Croatian domestic garlic, particularly at longer treatment time. The major decrease of phenolic acids in fried vegetables was also reported (5). Oxidative reactions are enhanced after processing of garlic, and phenolic acid losses could be due to the oxidative degradation, interaction between oxidized phenols and proteins or amino acids, and polymerization of oxidized phenols (4).

\section{HPLC analysis of organosulfur compounds in fresh and processed Croatian domestic garlic}

In the literature little data is available about the stability of the OSC during different processing and therefore this study identified effects of various treatments on the OSC content of Croatian domestic garlic cultivar. Disruption of garlic tissue stimulates the formation of allicin and other OSC and therefore the fresh Croatian domestic garlic was crushed and immediately analysed for OSC as a control sample. Other garlic samples were exposed to air (oxidation), blanched and fried, respectively, and analysed after 2, 5, 8 and 10 min of treatment. The composition and mass fractions of OSC in fresh Croatian domestic garlic and in processed garlic samples are given in Table 2. All garlic samples had the same OSC composition as fresh garlic, characterised by following compounds: methylsulfinylsulfanylmethane $\left(\mathrm{TiMe}_{2}\right)$, allicin $\left(\mathrm{TiAl}_{2}\right)$, mixtures of isomers 3-methylsulfinylsulfanylprop-1-ene and 3-methylsulfanylsulfinylprop-1-ene (TiMeAI/TiAIMe), (E)-1-prop-2-enylsulfinylsulfanylprop-1-ene and (E)-1-prop-2-enylsulfanylsulfinylprop-1-ene (TiPeAl/TiAlPe), and 1-methylsulfinylsulfanylprop-1-ene and (E)-1-methylsulfanylsulfinylprop-1-ene (TiMePe/TiPeMe) and an unidentified compound. These results are in agreement with the reported data (17). Dominant compound in fresh garlic was $\mathrm{TiMe}_{2}(9.88 \mathrm{~g} / 100 \mathrm{~g})$, which constituted $99.43 \%$ of total garlic OSC, followed by TiMeAI/TiAIMe $(0.26 \mathrm{~g} / 100 \mathrm{~g})$ and allicin $(0.18 \mathrm{~g} / 100 \mathrm{~g})$; Table 2 . This is partially in agreement with previous reports (25). Allicin is considered the most responsible

Table 2. Organosulfur compounds determined on fresh mass basis by HPLC UV/Vis PDA in fresh and processed (crushed, blanched, fried) Croatian domestic garlic after 2, 5, 8 and 10 min of treatment

\begin{tabular}{|c|c|c|c|c|c|c|c|c|}
\hline \multirow{2}{*}{$\begin{array}{l}\text { Croatian } \\
\text { domestic garlic }\end{array}$} & \multirow{2}{*}{$t / \min$} & TiMe2 & TiMeAl/TiAlMe & TiAl2 & TiPeAl/TiAlPe & TiMePe/TiPeMe & nd & TOTAL OSC \\
\hline & & \multicolumn{7}{|c|}{$w /(\mathrm{mg} / 100 \mathrm{~g})$} \\
\hline \multirow[t]{3}{*}{ Fresh } & 0 & $9881.83 \pm 4.88$ & $257.59 \pm 3.44$ & $185.62 \pm 1.59$ & $71.66 \pm 0.53$ & $49.38 \pm 0.37$ & $1.34 \pm 0.02$ & $10447.42 \pm 3.17$ \\
\hline & 2 & $(12887.30 \pm 4.31)^{d}$ & $(568.02 \pm 5.39)^{d}$ & $(318.59 \pm 2.09)^{d}$ & $(134.69 \pm 2.03)^{d}$ & $(94.98 \pm 1.37)^{\mathrm{d}}$ & $(13.84 \pm 0.27)^{d}$ & $(14017.42 \pm 2.25)^{d}$ \\
\hline & 5 & $(18547.16 \pm 6.11)^{\mathrm{a}}$ & $(1888.44 \pm 5.81)^{\mathrm{a}}$ & $(7772.42 \pm 10.54)^{\mathrm{a}}$ & $(4462.68 \pm 3.34)^{\mathrm{a}}$ & $(451.59 \pm 1.68)^{\mathrm{a}}$ & $(212.70 \pm 0.96)^{\mathrm{a}}$ & $(33334.99 \pm 13.46)^{\mathrm{a}}$ \\
\hline \multirow{4}{*}{ Crushed } & 8 & $(15910.95 \pm 4.70)^{\mathrm{b}}$ & $(958.19 \pm 3.99)^{\mathrm{b}}$ & $(2830.54 \pm 4.10)^{\mathrm{b}}$ & $(1473.02 \pm 4.15)^{\mathrm{b}}$ & $(206.21 \pm 1.42)^{b}$ & $(73.52 \pm 2.18)^{\mathrm{b}}$ & $(21452.43 \pm 9.73)^{\mathrm{b}}$ \\
\hline & 10 & $(14507.54 \pm 4.68)^{c}$ & $(921.95 \pm 4.40)^{c}$ & $(2172.04 \pm 4.50)^{c}$ & $(1189.37 \pm 4.31)^{c}$ & $(191.31 \pm 2.47)^{c}$ & $(64.68 \pm 0.87)^{c}$ & $(19046.89 \pm 1.87)^{c}$ \\
\hline & 2 & $(9778.50 \pm 2.92)^{\mathrm{b}}$ & $(87.96 \pm 2.38)^{b}$ & $(746.49 \pm 3.62)^{\mathrm{b}}$ & $(611.84 \pm 3.98)^{\mathrm{b}}$ & $(3.09 \pm 0.05)^{\mathrm{b}}$ & $(14.40 \pm 0.59)^{\mathrm{a}}$ & $(11242.28 \pm 7.51)^{\mathrm{a}}$ \\
\hline & 5 & $(9049.21 \pm 3.44)^{c}$ & $(13.74 \pm 0.34)^{c}$ & $(19.14 \pm 0.49)^{c}$ & $(16.65 \pm 0.49)^{c}$ & $(0.19 \pm 0.03)^{c}$ & $(0.68 \pm 0.03)^{b}$ & $(9099.61 \pm 3.10)^{c}$ \\
\hline \multirow{4}{*}{ Blanched } & 8 & $(8420.83 \pm 4.19)^{d}$ & $(4.53 \pm 0.39)^{d}$ & $(2.21 \pm 0.21)^{d}$ & $(3.09 \pm 0.08)^{d}$ & $(0.08 \pm 0.01)^{c, d}$ & $(0.14 \pm 0.01)^{\mathrm{b}}$ & $(8430.88 \pm 4.72)^{d}$ \\
\hline & 10 & $(8152.50 \pm 4.59)^{\mathrm{e}}$ & $(1.10 \pm 0.01)^{d}$ & $(1.54 \pm 0.03)^{d}$ & $(1.21 \pm 0.03)^{\mathrm{d}}$ & $(0.03 \pm 0.00)^{d}$ & $(0.06 \pm 0.01)^{b}$ & $(8156.44 \pm 4.62)^{\mathrm{e}}$ \\
\hline & 2 & $(4332.03 \pm 4.32)^{\mathrm{e}}$ & $(846.29 \pm 3.16)^{a}$ & $(7045.29 \pm 6.22)^{a}$ & $(4014.30 \pm 0.79)^{\mathrm{a}}$ & $(231.76 \pm 3.90)^{\mathrm{a}}$ & $(167.48 \pm 1.56)^{a}$ & $(16637.15 \pm 5.93)^{\mathrm{a}}$ \\
\hline & 5 & $(8786.55 \pm 5.23)^{\mathrm{d}}$ & $(188.39 \pm 1.37)^{c}$ & $(2341.95 \pm 2.95)^{b}$ & $(1662.90 \pm 4.09)^{\mathrm{b}}$ & $(93.25 \pm 1.66)^{\mathrm{b}}$ & $(59.31 \pm 0.57)^{\mathrm{b}}$ & $(13132.35 \pm 8.67)^{b}$ \\
\hline \multirow{2}{*}{ Fried } & 8 & $(9013.58 \pm 2.93)^{c}$ & $(74.04 \pm 0.17)^{\mathrm{e}}$ & $(992.42 \pm 2.96)^{c}$ & $(706.07 \pm 1.07)^{\mathrm{b}}$ & $(55.91 \pm 1.38)^{c}$ & $(16.65 \pm 0.49)^{c}$ & $(10858.67 \pm 0.04)^{c}$ \\
\hline & 10 & $(9250.34 \pm 4.24)^{\mathrm{b}}$ & $(122.66 \pm 2.11)^{d}$ & $(631.64 \pm 2.53)^{d}$ & $(425.49 \pm 2.01)^{d}$ & $(24.74 \pm 0.47)^{d}$ & $(13.62 \pm 0.37)^{c}$ & $(10468.49 \pm 2.51)^{d}$ \\
\hline
\end{tabular}

Values in the same row with the same letter in superscript do not differ statistically at $p \leq 0.05$.

TiMe2=methylsulfinylsulfanylmethane, TiMeAI/TiAIMe=3-methylsulfinylsulfanylprop-1-ene/3-methylsulfanylsulfinylprop-1-ene, $\mathrm{TiAl}$ =allicin, TiPeAI/TiAIPe=(E)-1-prop-2-enylsulfinylsulfanylprop-1-ene/(E)-1-prop-2-enylsulfanylsulfinylprop-1-ene, TiMePe/TiPeMe=1-methylsulfinylsulfanylprop-1-ene/(E)-1-methylsulfanylsulfinylprop-1-ene, nd=non-determined compounds, TOTAL OSC=total organosulfur compounds 
for the characteristic garlic aroma and fresh Croatian domestic garlic sample from our study had lower allicin mass fraction than cultivars from Korea and California (27). Difference in allicin content among various garlic cultivars has been observed and it is considered that it is directly related to genetic variations (1). The OSC content was different in all treated garlic samples as well as within the same sample, and it depends on the type of treatment, temperature and treatment time. Considering the fact that mechanical disruption of fresh garlic clove and high concentration of oxygen influence the activity of the intact enzymes, all identified OSC rapidly increased during 5 min (approx. 1- to 3-fold), and the most intensive increase was observed in TiPeAl/TiPeMe and allicin content.

The total OSC content decreased approx. 2-fold after $8 \mathrm{~min}$ of treatment and the highest loss, about 3-fold, was ofTiPeAl/TaAIPe and allicin probably due to their instability and degradation at elevated oxygen concentration. According to literature data, allicin rapidly decomposed into other sulfur-containing compounds over a relatively short time (28). Thermal treatments of garlic, frying and blanching, indicate heat instability of all OSC except $\mathrm{TiMe}_{2}$, probably as a result of enzyme action, thermal breakdown and effective diffusion into the cooking water during blanching. In fried garlic samples after 2 min of treatment all OSC increased and most dominant compound was allicin $(7.04 \mathrm{~g} / 100 \mathrm{~g}$; Table 2). The content of OSC in fried garlic was significantly reduced (in range from 21.07 to $37.08 \%$ ) as treatment time increased. For instance, allicin content decreased (-91.03\%), and we suppose that high temperature inactivated aliinase, which catalyses allicin synthesis or causes oxidation and denaturation of sulfur compounds. In another study, garlic samples lost all allicin (-99\%) immediately after frying. It is important to emphasise that allicin degradable products are bioactive compounds and they synergistically act with other garlic bioactive compounds (29).

Frying had negative effect on other OSC, also for example, the content of isomers TiPeAl and TiAlPe $(4.01 \mathrm{~g} / 100 \mathrm{~g})$ was significantly reduced after $10 \mathrm{~min}$ of treatment $(-89.41 \%$; Table 2). The frying at $120^{\circ} \mathrm{C}$ influenced the increasing $\mathrm{TiMe}_{2}$ content as treatment time increased; consequently, it seems that $\mathrm{TiMe}_{2}$ was more stable at high temperature than the other OSC. Stability of $\mathrm{TiMe}_{2}$ was also observed in blanched garlic samples, the highest content $(9.78 \mathrm{~g} / 100 \mathrm{~g}$; Table 2) was determined after 2 min of treatment in water bath at $100^{\circ} \mathrm{C}$ and as time of exposure increased, $\mathrm{TiMe}_{2}$ content slightly decreased. More susceptible to blanching were allicin and isomers TiPeAl and TiAlPe $(0.61 \mathrm{~g} / 100 \mathrm{~g}$; Table $2)$, the content of which rapidly decreased after 5 min of exposure $(-99.5 \%)$ to nearly undetectable levels after $10 \mathrm{~min}(-99.8$ $\%)$, and which are probably lost through leaching into the cooking water. Compared to other treatments, significant decrease of OSC was observed in blanched garlic samples. Statistical analysis shows that type of treatment had higher effect on OSC than treatment time. Literature data indicate that allicin content in garlic was time-dependent during cooking (6). Boiling, boiling at high pressure and frying caused losses of sulfur-containing components in onion (29) and Brassica vegetables, where glucosinolates are also present as sulfur-containing phytochemicals (30).

\section{CONCLUSIONS}

This study has shown that Croatian domestic garlic cultivar is a rich source of phenolic and organosulfur compounds (OSC), but the different processes such as crushing, blanching and frying significantly affected their content. Blanching caused significantly higher losses of total phenols than crushing and frying, while frying significantly decreased the total phenolic acid content compared to other treatments. Both blanching and frying significantly decreased the OSC content, particularly allicin, but only at longer treatment time. Crushed garlic exposed to air had higher antioxidant activity and the treatment time did not cause its significant decrease. Considering all the evidence, crushing can be suggested as the best method to preserve the most of the phenolic and OSC content. Since garlic is rarely consumed raw, short thermal processing at lower temperature should be considered.

\section{ACKNOWLEDGEMENTS}

This work was supported by the Croatian Science Foundation (grant number HRZZ-IP-2013-11-3035: Application of innovative technologies for production of plant extracts as ingredients for functional food). The authors wish to express their gratitude to Professor Veronika Kovač for help in nomenclature of organosulfur compounds.

\section{REFERENCES}

1. Montaño A, Beato VM, Mansilla F, Orgaz F. Effect of genetic characteristics and environmental factors on organosulfur compounds in garlic (Allium sativum L.) grown in Andalusia, Spain. J Agric Food Chem. 2011;59(4):1301-7.

https://doi.org/10.1021/jf104494j

2. Bozin B, Mimica-Dukić N, Samojlik I, Goran A, Igic R. Antioxidant properties of methanol extracts of wild garlics (genus Allium L., sect. Allium). Planta Med. 2008;74(9):969.

https://doi.org/10.1055/s-0028-1084119

3. Gorinstein S, Leontowicz H, Leontowicz M, Namiesnik J, Najman K, Drzewiecki J, et al. Comparison of the main bioactive compounds and antioxidant activities in garlic and white and red onions after treatment protocols. J Agric Food Chem. 2008;56(12):4418-26.

https://doi.org/10.1021/jf800038h

4. Martins N, Petropoulos S, Ferreira ICFR. Chemical composition and bioactive compounds of garlic (Allium sativum L.) as affected by pre- and post-harvest conditions: A review. Food Chem. 2016;211:41-50.

https://doi.org/10.1016/j.foodchem.2016.05.029

5. Miglio C, Chiavaro E, Visconti A, Fogliano V, Pellegrini N. Effects of different cooking methods on nutritional and physicochemical characteristics of selected vegetables. J Agric Food Chem. 2008;56(1):139-47.

https://doi.org/10.1021/jf072304b10

6. de Queiroz YS, Antunes PB, Vicente SJV, Sampaio GRJ, Shibao J, Bastos DHM, et al. Bioactive compounds, in vitro 
antioxidant capacity and Maillard reaction products of raw, boiled and fried garlic (Allium sativum L.). Int. J Food Sci Technol. 2014;49(5):1308-14.

https://doi.org/10.1111/ijfs.12428

7. Jiménez-Monreal AM, García-Diz L, Martínez-Tomé M, Mariscal MMMA, Murcia MA. Influence of cooking methods on antioxidant activity of vegetables. J Food Sci. 2009;74(3): 97-103.

https://doi.org/10.1111/j.1750-3841.2009.01091.x

8. Locatelli DA, Altamirano JC, Gonzalez RE, Camargo AB. Home-cooked garlic remains a healthy food. J Funct Foods. 2015;16:1-8.

https://doi.org/10.1016/j.jff.2015.04.012

9. Kinalski T, Noreña CPZ. Effect of blanching treatments on antioxidant activity and thiosulfinate degradation of garlic (Allium sativum L.). Food Bioproc Tech. 2014;7(7):2152-7. https://doi.org/10.1007/s11947-014-1282-1

10. Locatelli DA, Nazareno MA, Fusari CM, Camargo AB. Cooked garlic and antioxidant activity: Correlation with organosulfur compound composition. Food Chem. 2017;220:219-24. https://doi.org/10.1016/j.foodchem.2016.10.001

11. Kim JS, Kang OJ, Gweon OC. Comparison of phenolic acids and flavonoids in black garlic at different thermal processing steps. J Funct Foods. 2013;5(1):80-6.

https://doi.org/10.1016/j.jff.2012.08.006

12. Beato VM, Orgaz F, Mansilla F, Montaño A. Changes in phenolic compounds in garlic (Allium sativum L.) owing to the cultivar and location of growth. Plant Foods Hum Nutr. 2011;66(3):218-23.

https://doi.org/10.1007/s11130-011-0236-2

13. Khar A, Banerjee K, Jadhav MR, Lawande KE. Evaluation of garlic ecotypes for allicin and other allyl thiosulphinates. Food Chem. 2011;128(4):988-96.

https://doi.org/10.1016/j.foodchem.2011.04.004

14. Chen S, Shen X, Cheng S, Li P, Du J, Chang Y, Meng H. Evaluation of garlic cultivars for polyphenolic content and antioxidant properties, PloS ONE. 2013;8(11):e79730. https://doi.org/10.1371/journal.pone.0079730

15. Dragović-Uzelac V, Levaj B, Bursać D, Pedisić S, Radojčić I, Biško A. Total phenolics, flavonoids, non-flavonoids, anthocyanins and antioxidant capacity assays of selected fruits. Agric Conspec Sci. 2007;72(4):279-84.

16. ChemStation for LC and LC/MS Systems, Rev. C.01.03., Agilent Technologies Inc. Wilmington, DE, USA; 2001-2011.

17. Zorić Z, Dragović-Uzelac V, Pedisić S, Kurtanjek Ž, Elez Garofulić I. Kinetics of the degradation of anthocyanins, phenolic acids and flavonols during heat treatments of freezedried sour cherry Marasca paste. Food Technol Biotechnol. 2014;52(1):101-8.

18. Mondy N, Naudin A, Christides J P, Mandon N, Auger J. Comparison of GC-MS and HPLC for the analysis of Allium volatiles. Chromatographia. 2001;53(S1):S356-60.

https://doi.org/10.1007/Bf02490356

19. Bose S, Laha B, Banerjee S. Quantification of allicin by high performance liquid chromatography-ultraviolet analysis with effect of post-ultrasonic sound and microwave radiation on fresh garlic cloves. Pharmacogn Mag. 2014;10 (Suppl 2):288-93.

https://doi.org/10.4103/0973-1296.133279

20. STATISTICA, v. 10.0., StatSoft, Inc, Tulsa, OK, USA; 2012. Available from: http://www.statsoft.com.

21. Volk GM, Stern D. Phenotypic characteristics of ten garlic cultivars grown at different North American locations. HortScience. 2009;44(5):1238-47.

22. Podsędek A, Sosnowska D, Redzynia M, Koziołkiewicz M. Effect of domestic cooking on the red cabbage hydrophilic antioxidants. Int J Food Sci Technol. 2008;43(10):1770-7. https://doi.org/10.1111/j.1365-2621.2007.01697.x

23. Altemimi A, Lakhssassi N, Baharlouei A, Watson DG, Lightfoot DA. Phytochemicals: extraction, isolation, and identification of bioactive compounds from plant extracts. Plants. 2017;6(4):42-65.

https://doi.org/10.3390/plants6040042

24. Baljeet SY, Roshanlal Y, Ritika BY. Effect of cooking methods and extraction solvents on the antioxidant activity of summer squash (Cucurbita pepo) vegetable extracts. Int. Food Res. J. 2016;23(4):1531-40.

25. Drozd M, Thomas M, Nowak R, Determination of phenolic acids in raw garlic (Allium sativum L.) and onion (Allium cepa L.) bulbs. Annales UMCS. 2011;24:121-7.

26. Sultana B, Anwar F. Flavonols (kaempeferol, quercetin, myricetin) contents of selected fruits, vegetables and medicinal plants. Food Chem. 2008;108(3):879-84.

https://doi.org/10.1016/j.foodchem.2007.11.053

27. Yoo M, Lee S, Kim S, Hwang JB, Choe J, Shin D. Composition of organosulfur compounds from cool- and warmtype garlic (Allium sativum L.) in Korea. Food Sci Biotechnol. 2014;23(2):337-44.

https://doi.org/10.1007/s10068-014-0047-y

28. Prati P, Henrique CM, de Souza AS, Nuñez da Silva VS, Bertolodo Pacheco MT. Evaluation of allicin stability in processed garlic of different cultivars. Food Sci Technol (Campinas). 2014;34(3):623-8.

https://doi.org/10.1590/1678-457X.6397

29. Cardelle-Cobas A, Corzo N, Soria AC, Villamiel M. A comprehensive survey of garlic functionality. In: Pacurar $M$, Krejci G, editors. Garlic consumption and health. New York, NY, USA: Nova Science Publishers, Inc.; 2010. pp. 1-60.

30. Hansen EA, Folts JD, Goldman IL. Steam-cooking rapidly destroys and reverses onion-induced antiplatelet activity. Nutr J. 2012;11(1):76.

https://doi.org/10.1186/1475-2891-11-76 